\title{
The Efficacy of Nasal Steroids in Treatment of Otitis Media with Effusion: A Comparative Study
}

\author{
Mohammad Waheed El-Anwar ${ }^{1} \quad$ Ahmad Abdel-Fattah Nofal $^{1} \quad$ Alaa Omar Khazbak ${ }^{1}$ \\ Ahmad Ebrahim El Sayed ${ }^{1}$ Mohammad Ramadan Hassan ${ }^{1}$ \\ ${ }^{1}$ Department of Otorhinolaryngology-Head and Neck Surgery, \\ Zagazig University, Zagazig, Egypt \\ Int Arch Otorhinolaryngol 2015;19:298-301.
}

\begin{abstract}
Introduction Otitis media with effusion (OME) continues to be an important pediatric clinical problem, and more studies are needed to decide the proper treatment for it. Objective To assess the efficacy of nasal steroids in the management of OME by comparing its results with that of oral steroid and that of nasal saline spray as placebo. Methods This study was carried on 60 patients with OME who were divided into three groups: in group 1, 20 patients received mometasone furoate spray, one puff in each nostril daily, for 3 months; in group 2, 20 patients received oral prednisolone, $5 \mathrm{mg}$ three times per day for the first 3 weeks; in group 3, 20 patients received nasal saline spray, one puff in each nostril daily for 3 months.
Keywords
- otitis media with effusion
- nasal steroids
- tympanometry

Results A highly significant difference between systemic or topical (nasal spray) steroid therapy and saline nasal spray was detected $(p<0.001)$, and the difference between systemic and topical steroid was nonsignificant $(p>0.05)$.

Conclusion Nasal steroid spray can be used as an effective treatment for OME, giving a significant result similar to systemic steroid. Further studies are needed to investigate its use for longer duration and in recurrent cases.
\end{abstract}

\section{Introduction}

Otitis media with effusion (OME) is defined as effusion in the middle ear without signs and symptoms of an acute infection. It is a leading cause of hearing impairment in children, and its early and proper management can avoid hearing and speech impairment, which can cause developmental delay in children. ${ }^{1}$

Although many conditions such as enlarged adenoids, cleft palate, Down syndrome, Kartagener syndrome, and nasopharyngeal neoplasm are related to the role of eustachian tube (ET) dysfunction in the pathogenesis of OME, allergic, immunologic, and infectious factors have also been claimed. 2,3

Treatment of OME is still a controversial issue, ${ }^{1,4}$ as conventional treatment approaches fail to provide satisfactory and permanent relief of otologic symptoms. ${ }^{1,4-7}$ There is lack of proven effectiveness of the commonly given treatments, such as antibiotics, decongestants, and antihistamines, which are potentially harmful and have disadvantages. Few studies have investigated topical intranasal steroids for OME treatment, and in those studies, the duration of intranasal steroid application was short and there was no hearing evaluation. ${ }^{8-11}$

The aim of this study was to assess the efficacy of nasal steroids in management of OME by comparing its results with that of oral steroids and that of nasal saline spray as a placebo.

\section{Methods}

Sixty patients with OME over a period from January 2012 to December 2013 were included in this study. The study was approved by the Institutional Review Board. Informed written received

December 9, 2014

accepted

January 22, 2015

published online

March 18, 2015
DOI http://dx.doi.org/

10.1055/s-0035-1548535. ISSN 1809-9777.
Copyright (c) 2015 by Thieme Publicações License terms Ltda, Rio de Janeiro, Brazil

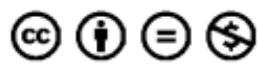


consent was obtained from the parents of the children studied after explanation of the research purpose.

The children included in the study had OME with type B tympanogram and conductive hearing loss. Patients previously managed by ventilation tube and those who had cleft palate, previous history of radiotherapy, or symptomatizing adenoid or enlarged adenoid as verified by endoscopy or radiology were excluded from the study. The patients were divided into three equal groups. In group 1, 20 patients received momentasone furoate spray, one puff in each nostril daily for 3 months. In group 2, 20 patients received oral prednisolone, $5 \mathrm{mg}$ three times per day for 3 weeks then gradual withdrawal over 2 weeks. In group 3, 20 patients received nasal saline spray, one puff in each nostril daily for 3 months. All patients received amoxicillin for the first 10 days.

Otoscopic examination, basic audiological evaluation including pure tone audiometry, and immittancemetry were performed before treatment and repeated at 3 and 6 months after treatment. The evaluation was performed using Zodiac tympanometer model 902 and Madsen Audiometer model Itera II (Denmark). Examiners were blinded to the type of treatment.

Tympanometry results were distinguished into four grades as classified by El-Anwar et $a^{12}$ : type $\mathrm{A}$, normal curve (pressure $+50 /-99 \mathrm{H}_{2} \mathrm{O}$ ); type $\mathrm{C} 1$ (negative pressure -100 / $-199 \mathrm{~mm} \mathrm{H}_{2} \mathrm{O}$ ); type $\mathrm{C} 2$ (negative pressure -200/-394 mm $\mathrm{H}_{2} \mathrm{O}$ ); type $\mathrm{B}$ (flat curve). ${ }^{2,3,11}$ The average hearing thresholds at $500 \mathrm{~Hz}$ and 1,2 , and $4 \mathrm{kHz}$ were used in the statistical comparison.

Follow-up clinical examinations were done once per week for 3 weeks, at the end of treatment, and then monthly for 6 months. OME resolution (disease-free status) was defined as normal findings on otoscopy, type A tympanogram, and improved hearing (thresholds to normal range). ${ }^{2}$

The efficacy of nasal steroid for management of OME was compared with that of oral steroid and that of nasal saline spray as placebo.

Recurrence of OME was evaluated by patient complaint of hearing loss, otoscopic criteria of OME, and immittancemetry.

Comparison between data of preoperative and postoperative evaluations was done by chi-square test and analysis of variance (version 17, SPSS Statistical Package for Social Sciences; SPSS, Inc., Chicago, Illinois, United States).

\section{Results}

Sixty patients with bilateral OME (120 ears) were included in this study, 33 male (55\%) and 27 female (45\%) subjects, equally distributed in the three groups (20 patients, 40 ears for each group). Their ages ranged from 6 to 14 years with a mean ( \pm standard deviation) of $8.7( \pm 2.45)$ years and with age matched between groups ( - Table $\mathbf{1}$ ).

Although before treatment, all ears showed tympanic membrane retraction, loss of luster, and type B tympanometry, fluid level or air bubbles were observed behind 6 ears in group A, 8 ears in group B, and 7 ears in group C. All clinical findings improved significantly after steroid treatment (na- sally or systemic). However, no significant change with placebo (nasal saline spray) and no significant difference between clinical finding between steroid spray and systemic steroid were reported ( $\mathbf{-}$ Table $\mathbf{1}$ ).

Post-nasal steroid treatment, tympanometry revealed type B curve in 2 ears (5\%), type C1 curve in 6 ears (15\%), type $\mathrm{C} 2$ in 4 ears (10\%), and type A (normal) in 28 ears (70\%). Post-systemic steroid treatment, tympanometry revealed type B curve in 6 ears (15\%), type C1 curve in 2 ears (5\%), type C2 in 6 ears (15\%), and type A (normal) in 26 ears (65\%). Post-nasal saline treatment, tympanometry revealed type B curve in 22 ears (55\%), type C1 curve in 4 ears (10\%), type C2 in 6 ears (15\%), and type A (normal) in 8 ears $(20 \%)$ (-Table 2).

The difference between nasal steroid and saline was highly significant (chi-square $=28.575, p<0.001$ ). The difference between systemic steroid and nasal saline was highly significant (chi-square $=19.339, p<0.001$ ). The difference between systemic and nasal steroid was nonsignificant (chisquare $=4.47, p=0.21$ ).

The hearing thresholds improved markedly, statistically and clinically, after treatment with oral and nasal corticosteroid. However, thresholds improved minimally after saline use. No significant difference was found between posttreatment hearing thresholds and those of 6-month follow-up (-Table 3). There was statistically nonsignificant difference between amount of improvement of hearing thresholds induced by oral and topical corticosteroid ( - Table 4 ).

\section{Discussion}

OME is a very common disease, especially in children. It is a multifunctional disease, and it has long been recognized that ET dysfunction predisposes to OME. Serious scientific data support an allergy etiology in the pathogenesis of OME. ${ }^{7,8}$

As the nasal mucosa is continuous with the middle ear mucosa, the changes that can be seen in the nasal mucosa continue into the middle ear. Therefore, ET dysfunction is considered as the underlying pathophysiological process for most cases of chronic otitis media.

Few studies have addressed the efficacy of nasal steroid spray on OME; two studies report that topical intranasal steroid is beneficial either alone or with an antibiotic in treating OME at 1 month. However, the findings were not statistically significant, ${ }^{9,10}$ with no evidence of benefit beyond 2 weeks of treatment. ${ }^{10}$ On the other hand, an intranasal steroid for up to 6 weeks was found to be effective in patients with OME and adenoid hypertrophy. ${ }^{8}$ In the current study, intranasal steroid for 12 weeks was found to be effective in patients with OME and without adenoid hypertrophy.

Thomas et al, $^{9}$ after their systematic review, concluded that data to support the use of nasal steroids alone were insufficient. However, their results were based on a prospective placebo-controlled study involving children with both allergic rhinitis and OME.

In the current study, significant improvement occurred in the tympanogram type and pure tone hearing thresholds 
Table 1 Results of posttreatment clinical examination

\begin{tabular}{|l|l|l|l|l|l|l|l|l|}
\hline Clinical observation at otoscopy & \multicolumn{2}{l|}{$\begin{array}{l}\text { Group A } \\
\text { (momentasone } \\
\text { furoate spray) }\end{array}$} & $\begin{array}{l}\text { Group B (oral } \\
\text { prednisolone) }\end{array}$ & \multicolumn{2}{l|}{$\begin{array}{l}\text { Group C (nasal } \\
\text { saline) }\end{array}$} & Chi-square test & $p$ Value \\
\cline { 2 - 9 } & No. of ears & $\%$ & No. of ears & $\%$ & No. of ears & $\%$ & \\
\hline TM retraction & 12 & 30 & 12 & 35 & 28 & 70 & 6.76 & $0.03 \mathrm{~S}$ \\
\hline Fluid level or air bubbles behind & 1 & 2.5 & 2 & 5 & 7 & 5 & 15.35 & $<0.001 \mathrm{HS}$ \\
\hline Loss of luster & 10 & 25 & 12 & 30 & 30 & 75 & 24.7 & $<0.001 \mathrm{HS}$ \\
\hline Normal TM & 28 & 70 & 28 & 70 & 10 & 25 & 21.8 & $<0.001 \mathrm{HS}$ \\
\hline & \multicolumn{2}{|l|l|}{ Chi-square $=0.43 ; p=0.93 \mathrm{NS}$} & & & & \\
\hline
\end{tabular}

Abbreviations: HS, highly significant; NS, nonsignificant; S, significant; TM, tympanic membrane.

Table 2 Results of posttreatment tympanometric curves

\begin{tabular}{|l|l|l|l|l|l|l|l|l|}
\hline \multirow{2}{*}{ Types of tympanometry curves } & \multicolumn{2}{l|}{$\begin{array}{l}\text { Group A } \\
\text { (momentasone } \\
\text { furoate) }\end{array}$} & \multicolumn{2}{l|}{$\begin{array}{l}\text { Group B (oral } \\
\text { prednisolone) }\end{array}$} & \multicolumn{2}{l|}{$\begin{array}{l}\text { Group C (nasal } \\
\text { saline) }\end{array}$} & Chi-square test & $p$ Value \\
\cline { 2 - 9 } & No. of ears & $\%$ & No. of ears & $\%$ & No. of ears & $\%$ & \\
\hline Type B & 2 & 5 & 6 & 15 & 22 & 55 & 36.64 \\
\hline Type C1 & 6 & 15 & 2 & 5 & 4 & 10 & \\
\hline Type C2 & 4 & 10 & 6 & 15 & 6 & 15 & \\
\hline Type A & 28 & 70 & 26 & 65 & 8 & 20 & \\
\hline & Chi-square $=4.47 ; p=0.21$ NS & & & \\
\hline
\end{tabular}

Abbreviations: HS, highly significant; NS, nonsignificant.

Table 3 Comparison between pre- and posttreatment average of hearing thresholds (improvement) and between posttreatment and 6-month follow-up (stability) using one-way ANOVA

\begin{tabular}{|l|l|l|l|l|}
\hline & Pretreatment $(\mathrm{dB}$ HL) & Posttreatment $(\mathrm{dB}$ HL) & 6-month follow-up (dB HL) & f-probability \\
\hline Oral corticosteroid & $33.6( \pm 3.2)$ & $15.3( \pm 2.8)$ & $15.7( \pm 2)$ & $\begin{array}{l}\text { I: } 0.000 \\
\text { II: } 0.953\end{array}$ \\
\hline Nasal corticosteroid & $33.7( \pm 2.4)$ & $14.8( \pm 2.8)$ & $14.4( \pm 1.9)$ & $\begin{array}{l}\text { I: } 0.000 \\
\text { II: } 0.941\end{array}$ \\
\hline Normal saline & $33.9( \pm 3.5)$ & $28( \pm 3.8)$ & $30( \pm 2.2)$ & $\begin{array}{l}\text { I: } 0.004 \\
\text { II: } 0.434\end{array}$ \\
\hline
\end{tabular}

Abbreviations: ANOVA, analysis of variance; HL, hearing level.

I: probability $(f)$ between pre-treatment and post-treatment evaluations.

II: probability (f) between post-treatment and 3-month post-treatment evaluations.

Table 4 Independent group $t$ test comparison between improvements of hearing thresholds induced by both administration routs of corticosteroid

\begin{tabular}{|l|l|l|l|}
\hline & Mean (SD) & $t$ Test & $p$ Value \\
\cline { 1 - 2 } Oral corticosteroid & $18.3 \mathrm{~dB} \mathrm{HL} \mathrm{(4.8)}$ & -0.29 & $0.78 \mathrm{NS}$ \\
\cline { 1 - 2 } Nasal corticosteroid & $18.9 \mathrm{~dB} \mathrm{HL} \mathrm{(3.5)}$ & & \\
\hline
\end{tabular}

Abbreviations: NS: nonsignificant; HL, hearing level; SD, standard deviation. 
after using corticosteroid medication, whether systemic or topical, highlighting their effective therapeutic role, which could be attributed to their combined antiallergic and antiinflammatory actions. Moreover, the stability of the results over 6 months' follow-up revealed an etiologic improvement rather than a symptomatic one. The minimal improvement of hearing thresholds noticed in the placebo group could be a cause of the initial antibiotic therapy in three management regimens and/or the improvement of the mucosal lining condition by regular wash by the saline solution.

The difference between systemic and nasal steroid was nonsignificant. Thus it is better to use nasal steroid as it minimizes systemic side effects of corticosteroids especially with mometasone furoate, which is known by its low bioavailability. It could be used for longer periods to maintain its effect for persistent relief of OME, in addition to its long-term control of the nasal allergy and the adenoid size, ${ }^{8,13}$ allowing time for the ET to fully recover. Moreover, steroids could exert their anti-inflammatory activity locally on the upper airways with limited or absent side effects. ${ }^{13}$

Our results agree with results of Butler and Van Der Voort, ${ }^{11}$ who extracted data from the published reports and concluded that both oral and topical intranasal steroids alone or in combination with an antibiotic led to a quicker resolution of OME in the short term.

\section{Conclusion}

In conclusion, nasal steroid spray is an effective treatment for OME, showing a result similar to systemic steroid but without the hazard of corticosteroid side effects. It can be used for longer, with much greater safety. It could also be helpful in controlling nasal allergy and the adenoid size, ${ }^{8,13}$ which are contributing factors in developing and recurring OME. Further studies are needed to investigate its use for longer duration and in recurrent cases.

\section{References}

1 Yousaf M, Inayatullah Khan F. Medical versus surgical management of otitis media with effusion in children. J Ayub Med Coll Abbottabad 2012;24(1):83-85

2 Bernstein JM, Lee J, Conboy K, Ellis E, Li P. Further observations on the role of IgE-mediated hypersensitivity in recurrent otitis media with effusion. Otolaryngol Head Neck Surg 1985;93(5):611-615

3 Tomonaga K, Kurono Y, Chaen T, Mogi G. Adenoids and otitis media with effusion: nasopharyngeal flora. Am J Otolaryngol 1989; 10(3):204-207

4 Kuo CL, Wang MC, Chu CH, Shiao AS. New therapeutic strategy for treating otitis media with effusion in postirradiated nasopharyngeal carcinoma patients. J Chin Med Assoc 2012;75(7):329-334

5 Ho WK, Wei WI, Yuen AP, Hui Y, Wong SH. Otorrhea after grommet insertion for middle ear effusion in patients with nasopharyngeal carcinoma. Am J Otolaryngol 1999;20(1):12-15

6 Tang NL, Choy AT, John DG, van Hasselt CA. The otological status of patients with nasopharyngeal carcinoma after megavoltage radiotherapy. J Laryngol Otol 1992;106(12):1055-1058

7 Naganawa S, Satake H, Iwano S, Fukatsu H, Sone M, Nakashima T. Imaging endolymphatic hydrops at 3 tesla using 3D-FLAIR with intratympanic Gd-DTPA administration. Magn Reson Med Sci 2008;7(2):85-91

8 Cengel S, Akyol MU. The role of topical nasal steroids in the treatment of children with otitis media with effusion and/or adenoid hypertrophy. Int J Pediatr Otorhinolaryngol 2006;70(4):639-645

9 Thomas CL, Simpson S, Butler CC, van der Voort JH. Oral or topical nasal steroids for hearing loss associated with otitis media with effusion in children. Cochrane Database Syst Rev 2006;(3):CD001935

10 Williamson I, Benge S, Barton S, et al. Topical intranasal corticosteroids in 4-11 year old children with persistent bilateral otitis media with effusion in primary care: double blind randomised placebo controlled trial. BMJ 2009;339:b4984

11 Butler CC, Van Der Voort JH. Oral or topical nasal steroids for hearing loss associated with otitis media with effusion in children. Cochrane Database Syst Rev 2002;(4):CD001935

12 El-Anwar MW, Amer HS, Elnashar I, Khazbak AO, Khater A. Effect of Central Inset Pharyngeal Flap for Velopharyngeal Insufficiency on Eustachian Tube Function. Laryngoscope 2014; published online: DOI: 10.1002/lary.25106

13 Berlucchi M, Valetti L, Parrinello G, Nicolai P. Long-term follow-up of children undergoing topical intranasal steroid therapy for adenoidal hypertrophy. Int J Ped Otorhinolaryngol 2007;72(8):1171-1175 